\title{
The Articulation of External and Internal Variables and the Industrial Prospects of Peripheral Societies
}

\section{Ennio Rodríguez}

This is a critical review of three conceptualisations of the impact of the global dynamics of the capitalist system on the internal processes of nation-states: it considers particularly how these three address the likelihood of an industrial transformation. from a perspective which stresses the importance of the global system in the determination of structural opportunities open to nation-states.' The formulations considered are those of Cardoso. Murray. and Bienefeld and Innes.

\section{Cardoso: the Notion of Dependency}

A difficulty that must be mentioned at the outset is that this prolific writer varies in the degree of indeterminacy he introduces in historical analysis. In this sense. it can be argued that his work lacks a coherent methodological position. The emphasis on structural determinations of historical outcomes. such as in the article Dependency and development in Latin America | 1972|. practically recedes to a form of historicism. in which-in some of the analyses of Brazil specifically |1973|-explanation seems not to attempt to transcend reasoned description. An immediate implication of this methodological oscillation is that he gives no unique answer to the question of the articulation of global and national dynamics. We can recognise at least two attempts to deal with the internalexternal relationships. but both are somewhat problematic.

First. according to Cardoso, dependency refers to that historical characteristic which expresses the specificity of the introduction of the capitalist mode of production in some social formulations. But this introduction is not perceived as offering the gains from trade which comparative advantage suggests. Rather. the resulting articulation with the global system is seen as a form of domination by the latter. He emphasises that the novelty of the hypothesis resides not in the recognition of external domination but in the description of the forms that it assumes|Cardoso \& Faletto 1979: 174-51.

In his controversy with Weffort. Cardoso has indicated that the notion of dependence is not a totalising concept-something which is semantically obvious. since the word implies dependence on something else. It refers to a situation that is conditioned and not

\footnotetext{
I Martin Godfrey. Theo Mars and Gloria Rodriguez provided comments on an earlier version of this paper: the remaining errors are. of course. the author's responsibility.
}

conditioning [Cardoso 1970:105-6]. This argument suggests two questions: what is the nature of the conditioning factor. and how is this determination or exploitative domination conceptualised?

Let us start with the second question. Cardoso himself offers some comments on the issue. The causation is not understood in a mechanical sense. There is no external determination of internal consequences. He even rejects analytical causation and proposes a casualsignificant type of relation of the external over the internal. This means that the external forces should be studied in terms of their influence on the network of internal social relations: in the book jointly written with Faletto. the notion of dependence

finds not only internal expression; but also its true character as implying a situation that structurally entails a link with the outside in such a way that what happens internally in a dependent country cannot he fully explained without taking into consideration the links that internal groups have with external ones. Dependence should no longer be considered an external variable: its analysis should be based on the relations between the different social classes within the dependent nations themselves. $\quad$ [Cardoso and Faletto 1979:22]

Thus. there is no general conceptualisation of the link between external and internal factors. Instead it has to be determined in each particular situation how the link acquires internal expression:

we do not speak of dependence in general, but of situations of dependency. $\quad$ [Cardoso 1970:411]

If this link is not conceptualised. the methodological proposition comes very close to teleological reconstruction of past events. The external is expressed in the configuration of internal interests and as such participates in the political struggle and. hence. in the historical process. The internal expression of foreign factors must be studied in particular case studies: they are not conceptualised as having any theoretical existence. Cardoso only offers the methodological proposition that they should be described in each situation and that they somehow participate in the definition of structural alternatives.

This lack of conceptualisation of the assumed relation of domination means that the question dependent on what"? has no theoretical pertinence in Cardoso's 
view. Presumably. research need only find internal expression of external factors, and since this expression is particular to the case study, so is the definition of the external factors. They remain as undefined entities that in each period and case are considered as internally expressed. In Cardoso/Faletto, they range from the British interests in raw materials, forms of investment of European capital at the end of the nineteenth century, the world economic crisis of the 1930s, movements in the terms of trade, flows of international capital, foreign debt, the development of US transnationals, to international politics $a$ la Kissinger. External links without any necessary similarity in theoretical status are introduced in each situation, the only condition being that change has to be explained in terms of groups and classes existing in the preceding situation:

development results ... from the interaction and struggles of social groups and classes that have specific ways of relating to each other. The social and political structure is modified insofar as new social classes and groups succeed in imposing their interests on or accommodating them to previous dominant classes in society.

|Cardoso and Faletto. 1979:14|

In our view. an attempt to tackle the issue of industrialisation prospects for 'dependent' societies would need to give a central place to the dynamics of the accumulation process - that is, to the constraints and possibilities which global as well as internal processes and structures imply.

For Cardoso, on the other hand, the fundamental theoretical problem is the elucidation of the structures of domination as a means for understanding the dynamics of class relations. These constitute his object of enquiry, and his conceptualisation - constructed accordingly reduces other phenomena to the effects they might have on political struggles. Global dynamics are seen in terms of their expression in class configurations. and political changes and capital accumulation acquire a similar very limited theoretical existence. In his lecture 'Dependency revisited' he emphasises:

It is clear that the class structure sets the limits for the agreements between groups. The need to increase accumulation of capital is one fixed point that helps determine the boundaries within which the expansion and maintenance of these power alliances, organised on such changeable bases, is possible. But this structural parameter must not be allowed to obscure and confuse the analysis of the internal contradictions that this type of political amalgam generates.

[1973a:34]

Consequently. if capital accumulation is to be considered as one fixed structural parameter the dynamics of capital accumulation end up with no theoretical space. In this formulation, the degree of historical indeterminacy Cardoso introduces makes it impossible to speak of laws of movement within the discourse; if processes such as accumulation are but a fixed point that influences class struggle, these laws can only be found in the real political action of real social agents and not in the structures and processes that are constituted in a conceptualised manner in the discourse.

In conclusion, the methodology of Cardoso's approach to the development problematic means that the issue of the industrialisation prospects of peripheral societies, which we consider central for the discussion of development strategies. cannot be posed. His characterisation of the current period in terms of the structure of domination within 'dependent' societies offers no idea of the limits to the process of industrialisation.

Dependent capitalism in the phase of industrialisation of the periphery under the impetus of international oligopolic capital is characterised $b v$ the development of a form of state based on an alliance between the multinational enterprise, state entrepreneurs and the local bourgeoise, through which these sectors generate their dominion over the rest of society.

[Cardoso and Faletto 1979:210. author s translation]

A more detailed specification of this structure of domination is what dependency amounts to, given the methodological protocol which indicates that the external should be described in terms of its effects on the internal power alliance. Therefore, we cannot determine whether some degree of industrial development, or indeed a full blown industrialisation, is possible, until it becomes an event that can be described a posteriori.

\section{A Second Formulation}

In some writings, Cardoso pays lip service to the theory of imperialism:

the idea of dependency is defined in the theoretical field of the theory of capitalism... what is at stake is not an alternative, but a complement. to the theon of imperialism.

[197.3a:24-5]

In his article 'Dependency and development in Latin America' there is an explicit attempt to present dependency in the context of imperialism. It is in this essay that we find a greater role for explanation in historical anatysis and, hence, for structural determination. Capital accumulation, technology and capital flows thus have theoretical pertinence.

In this context the problem of industrial development is posed: 
strictly speaking - if we consider that development and monopoly penetration in the industrial sectors of dependent economies are not incompatible. . . to what extent is it possible to sustain the idea of development in tandem with dependence?

[1972:89-90]

In the answer to this question dependency is defined not in terms of internal domination alliances but in the context of capital accumulation. There is an attempt to conceptualise relations between global and internal processes. emphasising the constraints they place on accumulation possibilities:

on the other hand, and in spite of internal economic development, countries tied to international capitalism by that type of linkage remain economically dependent, insofar as the production of the means of production (technology) is concentrated in advanced capitalist economies (mainly in the US).

In terms of the Marxist scheme of capital reproduction, this means that sector I/ the production of means of production)-the strategic part of the reproductive scheme-is virtually non-existent in dependent economies. Thus, from a broad perspective, the realisation of capital accumulation demands a productive complementarity which does not exist within the country.

| 1973a:90|

However, this argument seems to rest on an international division of labour which is already being undermined and the extent of this process is precisely what is at stake. Moreover, in another article. 'The contradictions of associated development , Cardoso offers evidence that the development of a capital goods sector is already taking place and, furthermore. towards the end he comments

it is even possible that in the future the dynamics of the economic system will cease to be based only on the sectors of consumer durables production (controlled by the multinationals) and will shift in the direction of a large-scale steel industry and the export of semi-processed and.mineral products.

[ 1976:47]

In short. the second formulation of dependency seems to depend on the description of the international division of labour. the possible undermining of which is precisely what motivates this theoretical enterprise. Thus. to state what used to be the case is of little help in addressing the issue of the constraints on those industrial transformations which are taking place.

Consequently. to the extent that we consider the conceptualisation of the structural possibilities which the global system poses to peripheral societies as relevant for political purposes. we find both Cardoso's notions of dependency unsatisfactory.

\section{Murray: Laws of Location of the Capitalist Mode of Production}

A theoretical development that seems to run counter to Cardoso is exemplified by Murray. In his article The internationalisation of capital and the nation states'. he poses the issue of the territorial noncoincidence of nation states and the increasing internationalisation of capital. He ends with the suggestion

that there was no necessary link between a capital and its area of extension, that capital was rather a political opportunist, and that existing states often suffered a decrease in their powers as a result of internationalisation. . | However|, for any analysis of imperialism. the elaboration of the connections between not only states, but the states and their capitals seems to me a first priority. Only then will we be in a position to present more fully what one might call the territorial dialectics of capitalism.

|1975:133|

Nevertheless. in another article | 1972]. where Murray attempts to identify the laws of geographical location of economic activity within the capitalist mode of production. categories are constructed with the assumption that economics and politics refer to separable social realms, the latter being derivable from the former. Additionally. the attempt to conceptualise global dynamics from an economistic perspective means that the issue of the nation-state and its internal dynamics appears rather blurred and. thus. the discussion of the relations between global and internal dynamics is virtually omitted.

Basing his anatysis on the competitive pressures inherent in capitalist production which lead to constant efforts to economise time. Murray identifies the existence of centripetal forces which provoke a tendency towards the formation of agglomerations of productive activities. However. against these economies of proximity considerations of minimisation of costs also set in motion countertendencies. The fixed location of resources and communication costs to and from the agglomeration centre might outweigh the savings the central location could provide. As a consequence.

the interplay of these forces results in a locational hierarchy of economic activity, in which each intermediate level both dominates and is dominated $\mid$ and $\mid$ with the development of capitalism the rankings in this hierarchy become increasingly stable: it is 
more and more difficult for any subordinate area to develop self-sustained growth, or to supplant a dominant agglomeration by virtue of being a late comer'.

[1972:186]

International firms appear as the dominant institutions in this frame, such that their activity not only manifests the laws of location of the mode of production but also reinforces them on a world scale. Consequently, their power hinders attempts to reallocate productive activities on a significant scale [1972:169]. Thus, a rationale is provided for worldwide capital flows which result in the strengthening of existing agglomerations, making it very difficult for subordinated poles to become industrial dominating centres.

However, this set of concepts seems to equate the theory of the capitalist mode of production with a conceptualisation of the dynamics present in the global system. This can be illustrated by the almost immediate extrapolation of the previously mentioned laws of geographical location to laws of the global system:

rather than treating the international economy as a summation of national units, it is more helpful I think to see it as a single, predominantly capitalist system, in which the geographical distribution of particular features of a capitalist system will be governed by market determined laws of location and only secondarily by the action of nation-states. Competitive firms, particularly international firms, become the dominant units of the system. States, which in part reflect the interests of these firms, are subordinate, modifying elements.

[1972:162]

If Cardoso conflated global and internal dynamics in the analysis of national structures of domination, Murray seems to travel in the opposite direction, treating internal dynamics as secondary modifiers of global processes. Thus, this subordinate role not only of states but also of nation-states reduces their theoretical pertinence to complements of the general laws of the mode of production/global system:

there is a correlation between the position in the geographical hierarchy and power, both the monopoly power of firms, and the political power of states... [ consequently| this power is used to reinforce the uneven geographical distribution of economic activity as determined by the market.

[1972:187]

In spite of our starting point which emphasises the importance of the global system in the discussion of the development processes and which entails the recognition of dynamics at this worldwide level, we would not be prepared to go as far as this.
Fundamental developmental issues such as capital accumulation and class struggle have a dynamic internal to the nation-state. This dynamic is linked to global processes but such processes do not justify a reduction of nation-states to secondary modifiers of omnipresent laws of motion. In particular, the inherent tendency to crises of the capitalist mode of production finds expression not only at the international level, but also, and more frequently, within the boundaries of particular nation-states.

This analysis of the formation of capital agglomerations made purely in terms of competitive pressures and profit maximisation behaviour overlooks the fact that these capital concentrations do not simply show a correlation with political structures but also that the origin of both was completely intertwined, such that the development of structures of production and political structures was mutually necessary in the face of the constraints posed by the imperial powers and other modes of production. Hence, for us, the discussion needs rather to concern the genesis of social formations in the context of an unstable and competitive global system, such that different combinations of internal structures and processes linked with the global ones define distinct modes of integration to the global system, which, to some extent, determine the possibilities of internal resource mobilisation. Such an alternative approach would enable questions such as the relation of nation-states with conceptually different national or international capitals and the implications in terms of accumulation to be posed, and allow discussions on the conditions under which a particular type of insertion to the global system becomes possible or ceases to be so. These central sets of issues find no response in Murray's frame.

\section{Bienefeld and Innes: International-National Capital Differentiation}

A theoretically less ambitious project is undertaken by Bienefeld and Innes in their article 'Capital accumulation and South Africa'. No theory of capitalist development is attempted, be it at the level of the mode of production or of the periphery of the capitalist system. In this sense their work cannot be strictly compared with the two previously discussed; nevertheless, the fact that they explicitly address the issue of the connections between the external links of an economy and its capacity to mobilise its internal resources [1976:51] makes it immediately relevant to the questions we are dealing with here.

The contribution is based on a two-fold differentiation between national and international capital. On the one hand, capital is differentiated according to the nature of the opportunities required to induce 
investment. This implies a rejection of distinctions based on passport, residence, birthplace or other characteristics of the owners [p31]. On the other hand, the dependence of capital on a given social formation is stressed:

the fact is that international capital is a social relation which must be based on some particular social formation which can ensure the conditions of its reproduction on an intemational scale [ $\mathrm{p} 33$ ].

This differentiation of the nature of capitals operating in the global capitalist system offers a means of conceptualising distinctive modes of integration to this system of particular nation-states.

The authors see the global system as incapable of achieving continuous full employment. Given a Marxian notion of a falling rate of profit, they expect crises to arise as a result of the tendency itself or of counteracting forces. A high rate of technical transformation which increases the productivity of labour far more than it raises the cost of production of the capital employed would cause the problem to reappear as one of scarcity of markets [ pp 32-3]. This intrinsic difficulty for the valorisation of capital also explains the tendency for capital flows as attempts to cope with these difficulties.

It is in this context of an unevenly expandable capitalist system that two different structural locations are recognised: a centre and a periphery. The centre is characterised as such because it is the operational base of a large concentration of capital, whose international activity it is able to guarantee. Conversely, a peripheral economy does not constitute such a base Ip 33].

These different modes of integration to the global system mean different possibilities of internal expansion of productive activities and, hence, different likely outcomes of class struggle. An imperial power can mitigate the fluctuations characteristic of capitalist growth, which also gives labour substantial leverage; a peripheral society is more exposed to the contradictions of accumulation, since capital can abandon it relatively readily and, thus, weaken the power of labour in its struggle with capital.

The rather general incapacity of peripheral societies to mobilise local resources is explained as crucially dependent on the external links of the economy:

one might simply envisage this connection between the extemal and the intemal in barter terms. If there is in some peripheral economy some mineral which is demanded in the intemational economy then intemational interests will seek to obtain that commodity at the lowest possible cost . . . If however a part of the mineral produced is appropriated by locally resident interests then there is an incentive either to exchange commodities for this remainder in the trade, or to engage in other forms of local production in order to obtain the international purchasing power generated by these commodities exports (p 35-6).

However, the activities of the state are crucially dependent on the level of foreign exchange earnings (p 36). This hypothesis of a link between external forces-international capital -and local capability of mobilising resources appears as a plausible explanation of the empirical observations which show the centrality of foreign exchange constraints and chronic unemployment and underemployment in the periphery. Moreover, cases like Kuwait and Canada do not challenge the approach insofar as there is no necessary association between peripheral integration and poverty, provided that the export capacity of the economy is high in relation to the size of the population (p 38).

Regarding the issue of international capital flows, this conceptualisation suggests that it is not so much economies of agglomeration which immediately determine the logic of these flows, as foreign exchange constraints. Once these flows operate on an international basis, the necessity of realising profits in hard currency in order to maintain this scale of operations re-emerges as an overall constraint on the processes of reallocation of labour according to the logic of international capital.

However, this conceptualisation is not unproblematic. It rests on two features of international capital - the internationality of investment opportunities to which it responds and the national character of its sociopolitical basis. These characteristics show no formal contradiction. Nevertheless, the use made of them for the definition of structural locations of nation-states in the global system does result in a tension which tends to obscure some rather fundamental issues.

The analysis of core economies stresses the fact that their national capital is also international and, hence, that their home base is constituted by the given social formation. In the case of peripheral societies, however, access to international capital depends on the capacity of the economy to generate foreign exchange, since the base of operations of this capital is rooted elsewhere. The problem of this conceptualisation is that it assumes the issue of the structural location of the economies is solved, and that, if a society is peripheral, then the analysis of the constraints on the accumulation process can follow. In this sense it could not be argued that a change of location in the structure of the system may 
be the result of expansion based on inflows of international capital: this would overlook the constraints already suggested.

Thus. Bienefeld and Innes conceptualisation seems to be saying that if the structural location of the economy is well defined then some constraints may be specified. The issue addressed seems to be the limits to peripheral development - to what extent can the economy mobilise its internal resources given its mode of integration into the global system? But the specific definition of articulation to the world system based on features of international capital overshadows other relevant questions analysis ought to be able to deal with. There is no direct response to the issue of changes in the structural location of particular nationstates. An immediate suggestion that the characterisation of these societies is inadequate is made by the case of the oil producing countries: the foreign exchange constraint might be eased but this seems to be less than sufficient for their industrialisation.

More insight into change in structural location might perhaps be gained if the second feature of international capital were emphasised more in the analysis of both central and peripheral societies. Questions such as what are the processes through which an economy may actually become a home base for a large concentration of international capital?' or. conversely. under what circumstances may a core economy cease to be the basis for the operations of international capital?' should be addressed. Thence. the concepts of centre and periphery could be further specified. For example. in the analysis of the British economy. which set of constraints should be considered? That is. how far is British national capital international at the same time? Or is it losing its national basis and seeking an alternative socio-political unit which may guarantee its international scale of operations? On the other hand. is it likely that the oil surplus may provide conditions for Mexican industrialisation? In other words. further theorisation of the characteristics of central and peripheral societies and of the processes of transition from one location to the other seems to be required.

\section{Concluding Remarks}

Finally. we would wish to query the level of abstraction at which the issue of the constraints to the industrialisa- tion process can meaningfully be tackled. The formulations considered attempt to respond to this issue at a fairly abstract level. For example. Murray's economistic approach to the laws of geographic location of the capitalist mode of production can be shown to leave out of consideration processes internal to nationstates and. hence. the whole problematic of their industrialisation. Bienefeld and Innes' reconstruction of the concepts 'centre' and 'periphery' in a political economy context explicitly addresses the issue of the limits to capitalist development in the periphery. but their set of concepts. although illuminating on the nature of international capital. is insufficient to tackle the enterprise they attempt.

It might seem. therefore. that we end up endorsing Cardoso's suggestion of a movement to the concrete. to an analysis of situations of dependency. But this would entail a retreat from any analy tical consideration of the limits of capitalist development in the periphery. After dependency's initial onslaught on capitalism because of the stringent limits to development it seemed to impose on dependent societies. Cardoso represents a reaction-characteristic of many dependency authors - which completely disregards the analysis of constraints on accumulation except insofar as they might influence political structures. His movement to the concrete as a discussion of structures of domination represents an abandonment of the problematics of material development.

So the issue of the limits on industrialisation appears not to have a simple abstract answer. Moreover. the experience of South Korea and Israel might suggest more than one route exists to join the competitive club of high wage industrial societies. The discussion should perhaps proceed at a more concrete level. allowing the introduction of conjunctural features of the global economy - movements towards protectionism. development of trade areas. military confrontations. etc-as having implications for the constraints imposed upon the material and political development of peripheral societies. This. however. is a discussion which cannot make any progress in the absence of a theory of the expansive capacity of the capitalist system and its centripetal and centrifugal forces.

note: for references. see bibliography at the end of this Bulletin. 